\title{
L-carnitine suppresses transient receptor potential vanilloid type 1 activity and myofibroblast transdifferentiation in human corneal keratocytes
}

\author{
Elizabeth Turan ${ }^{1} \cdot$ Monika Valtink $\mathbb{D}^{2} \cdot$ Peter S. Reinach $\mathbb{1}^{3} \cdot$ Annett Skupin ${ }^{2} \cdot$ Huan Luo ${ }^{1} \cdot$ Tobias Brockmann $^{1,4,5}$. \\ Marah Hussain Omar Ba Salem ${ }^{1} \cdot$ Uwe Pleyer $^{1} \cdot$ Stefan Mergler (iD ${ }^{1}$
}

Received: 14 March 2020 / Revised: 4 January 2021 / Accepted: 4 January 2021 / Published online: 26 February 2021

(c) The Author(s) 2021. This article is published with open access

\begin{abstract}
Corneal stromal wound healing is a well-balanced process promoted by overlapping phases including keratocyte proliferation, inflammatory-related events, and tissue remodeling. L-carnitine as a natural antioxidant has shown potential to reduce stromal fibrosis, yet the underlying pathway is still unknown. Since transient receptor potential vanilloid 1 (TRPV1) is a potential drug target for improving the outcome of inflammatory/fibrogenic wound healing, we investigated if Lcarnitine can mediate inhibition of the fibrotic response through suppression of TRPV1 activation in human corneal keratocytes (HCK). We determined TRPV1-induced intracellular calcium transients using fluorescence calcium imaging, channel currents by planar patch-clamping, and cell migration by scratch assay for wound healing. The potential L-carnitine effect on TRPV1-induced myofibroblast transdifferentiation was evaluated by immunocytochemical detection of alpha smooth muscle actin. RT-PCR analysis confirmed TRPV1 mRNA expression in HCK. L-carnitine $(1 \mathrm{mmol} / \mathrm{l})$ inhibited either capsaicin (CAP) $(10 \mu \mathrm{mol} / \mathrm{l})$, hypertonic stress $(450 \mathrm{mOsmol} / \mathrm{l})$, or thermal increase $\left(>43^{\circ} \mathrm{C}\right)$ induced $\mathrm{Ca}^{2+}$ transients and corresponding increases in TRPV1-induced inward and outward whole-cell currents. This was accompanied by suppression of injury-induced increases in myofibroblast transdifferentiation and cell migration. In conclusion, L-carnitine contributes to inhibit stromal scarring through suppressing an injury-induced intrinsic TRPV1 activity that is linked with induction of myofibroblast transdifferentiation in HCK cells.
\end{abstract}

\section{Introduction}

Human corneal keratocytes (HCK) or fibroblasts are interspersed between orthogonally arranged layers of collagen

Stefan Mergler

stefan.mergler@charite.de

1 Klinik für Augenheilkunde, Charité-Universitätsmedizin Berlin, corporate member of Freie Universität Berlin, HumboldtUniversität zu Berlin and Berlin Institute of Health, Berlin, Germany

2 Institute of Anatomy, Faculty of Medicine Carl Gustav Carus of the TU Dresden, Dresden, Germany

3 School of Ophthalmology and Optometry, Wenzhou Medical University, Wenzhou, PR China

4 Berlin Institute of Health (BIH), Kapelle-Ufer 2, 10117 Berlin, Germany

5 Department of Ophthalmology, Universitätsmedizin Rostock, Rostock, Germany lamellae in the stroma. They are essential for maintaining corneal structure and transparency as they express stromal collagen fibers and different constituents of the extracellular matrix [1]. Under a quiescent condition, HCK elaborate constituents contributing to the formation of an organized collagenous transparent framework stroma, but during exposure to various stresses or infection HCK can be induced to undergo transdifferentiation into fibroblasts and myofibroblasts. This transition is essential for inducing the responses underlying wound repair and restoration of normal visual function. However, if this response is dysfunctional as a consequence of excessive fibroblast activation and transdifferentiation into myofibroblasts, the cornea can undergo opacification due to excessive irreversible scarification [2].

Injury-induced corneal scarring fibrosis and opacification are mediated through TRPV1 activation upregulating TGF $\beta$-expression which in turn promotes keratocyte transdifferentiation into myofibroblasts and increases in smooth muscle $\alpha$-actin expression [3]. This finding in concert with the identification of functional expression of TRPV1 on 
fibroblasts help explain why this non-selective ion channel is a recognized target to suppress myofibroblast transdifferentiation and corneal scarring. Such an outcome is expected to improve restoration of tissue transparency as a consequence of wound healing induced by severe injury or infection $[4,5]$. On the other hand, there is a caveat to this approach since epithelial TRPV1 activation instead promotes wound closure of this tissue. In order to circumvent this complication, intrastromal injection of an antagonist may be an option if it only blocks TRPV1 on stromal keratocytes and fibroblasts [6].

Osmoprotective agents have also been identified which lessen injury-induced stimulation of signaling pathways promoting tissue scarring during wound healing. Carnitine is one such agent ( $\beta$-hydroxy- $\gamma$-N-trimethylaminobutyric acid) [7]. It is a nutritional supplement widely distributed in foods of animal origin. A protective effect of L-carnitine was described in retinal pigment epithelial cells [8] and human corneal epithelial cells (HCEC) [9, 10]. In conjunctival epithelial cells ( $\mathrm{HCjEC}), \mathrm{L}$-carnitine reduced hypertonic-induced cell shrinkage through interacting with TRPV1 channels [11]. L-carnitine also functions as an osmoprotectant to suppress inflammatory responses via inhibiting TRPV1 linked signaling pathway in hyperosmotically stressed HCEC [9]. Finally, L-carnitine reduced oxidative stress-induced upregulation and stimulation of matrix metalloproteinase (MPs) activity resulting from exposure to hyperosmolarity in HCEC [10, 12]. These results prompted us to determine if L-carnitine application also reduces corneal stromal responses underlying opacification through inhibiting TRPV1 activation on HCK.

We show here that L-carnitine suppresses TRPV1 activation induced by exposure to either capsaicin (CAP), elevated temperature, or hypertonic stress in HCK. In addition, Lcarnitine suppressed injury-induced increases in HCK migration. Its potential usefulness as a therapeutic agent was demonstrated by showing that it inhibited TRPV1-induced keratocyte transdifferentiation into myofibroblasts. This result is relevant since it is known that this transition underlies corneal scarring and opacification, which can be symptomatic in patients chronically afflicted with stromal infection.

\section{Materials and methods}

\section{Cell culture of HCK}

SV40-immortalized HCK cells derived from a human cornea were used as a representative cell model of corneal keratocytes [13-15]. HCK identity was validated based on confirming specific keratocyte biomarker expression [4]. Cells were grown in DMEM medium containing 10\% fetal calf serum as well as penicillin/streptomycin in a humidified
$5 \% \mathrm{CO}_{2}$ incubator at $37^{\circ} \mathrm{C}$. For the electrophysiological measurements, cell confluence ranged between 60 and $80 \%$. Over this range of confluence, their electrophysiological characteristics were invariant [4].

\section{RNA isolation, RT-PCR, and sequencing}

HCK cells were seeded in T25 flasks and grown to confluence. Total RNA was extracted using TriFast ${ }^{\mathrm{TM}}$ (PeqLab, by VWR, Darmstadt, Germany) according to the manufacturer's instructions. RNA concentration and purity were determined with a NanoPhotometer ${ }^{\mathrm{TM}}$ (Implen $\mathrm{GmbH}$, Munich, Germany) and it was stored at $-80^{\circ} \mathrm{C}$ until further use. RNA ( $1.8 \mu \mathrm{g}$ per sample) was reverse transcribed with RevertAid H minus first strand cDNA synthesis kit (Thermo Fisher, Waltham, USA) according to the manufacturer's instructions in a total volume of $20 \mu \mathrm{l}$, and cDNA was stored at $-80{ }^{\circ} \mathrm{C}$ until further use. PCR was performed with a $2 \mu \mathrm{l}$ cDNA mixture in a total volume of $35 \mu$ using Taq polymerase and $0.2 \mathrm{nmol} / \mu \mathrm{l}$ of each forward and reverse primer (intron spanning, 5'-CCCCCGATAGCTCCTACAAC-3' and $3^{\prime}$-AAGGCCTTCCTCATGCACT-5', TRPV1 mRNA accession number NM_018727) after initial $95^{\circ} \mathrm{C}$ for $3 \mathrm{~min}$ over 35 cycles of $95^{\circ} \mathrm{C}$ for $30 \mathrm{~s}, 64^{\circ} \mathrm{C}$ for $30 \mathrm{~s}$ and $72^{\circ} \mathrm{C}$ for $45 \mathrm{~s}$, finalized by $72^{\circ} \mathrm{C}$ for $7 \mathrm{~min}$ and a temperature hold at $4{ }^{\circ} \mathrm{C}$ in a Techne TC-512 gradient thermal cycler (Staffordshire, UK), yielding a 295 bp product. Samples with RNAse- and DNAse-free $\mathrm{H}_{2} \mathrm{O}$ instead of cDNA template and samples that were proceeded without reverse transcriptase in the reverse transcription reaction served as nontemplate controls. Total RNA from a confluent human corneal endothelial cell line (HCEC-12) served as positive control [16]. PCR products were electrophoresed on a $1.5 \%$ agarose gel at $120 \mathrm{~V}$ for $1.75 \mathrm{~h}$ and visualized with ethidium bromide. Bands were cut out and DNA was eluted from the agarose using MP Biomedicals ${ }^{\mathrm{TM}}$ Geneclean ${ }^{\mathrm{TM}}$ Turbo Kit (Thermo Fisher) in a total elute volume of $30 \mu \mathrm{l}$. Eluted PCR products were sequenced (Eurofins Genomics GmbH, Ebersberg, Germany) and sequencing results were checked with NCBI Blast ${ }^{\circledR}$ software (https://blast.ncbi.nlm.nih.gov).

\section{Fluorescence calcium imaging}

HCK cells were pre-incubated with culture medium containing $1 \mu \mathrm{mol} / \mathrm{l}$ fura-2/AM for $\approx 40 \mathrm{~min}$. The loading was stopped with a Ringer-like (control) solution containing (mmol/l): $150 \mathrm{NaCl}, 6 \mathrm{CsCl}, 1 \mathrm{MgCl}_{2}, 10$ glucose, 10 HEPES, and $1.5 \mathrm{CaCl}_{2}$ at $\mathrm{pH} 7.4$ and $317 \mathrm{mOsmol} / 1$ [17]. At room temperature $\left(\approx 23^{\circ} \mathrm{C}\right)$, intracellular free $\mathrm{Ca}^{2+}\left(\left[\mathrm{Ca}^{2+}\right]_{\mathrm{i}}\right)$ levels were measured based on fura- 2 emission at $510 \mathrm{~nm}$ resulting from alternating excitation in a $5 \mathrm{~s}$ loop at 340 and $380 \mathrm{~nm}$ with a digital imaging system (Olympus Europa Holding GmbH, Hamburg, Germany). Cells were cultured 
on coverslips (diameter $15 \mathrm{~mm}$ ) and put in a chamber containing the aforementioned Ringer-like solution. Single cells were selected and designated as regions of interest. Cells were exposed to UV-light within a 5-s interval using a LED light source (LED-Hub by Omikron, Rodgau-Dudenhofen, Germany). The images were simultaneously recorded with a digital camera (Olympus XM-10) and $f_{340 \mathrm{~nm}} / f_{380 \mathrm{~nm}}$ fluorescence ratios, which are proportional to $\left[\mathrm{Ca}^{2+}\right]_{\mathrm{i}}$, were calculated by cellSens software (Olympus Europa Holding GmbH, Hamburg, Germany). Fluorescence ratios were normalized (control set to 0.1) and averaged (with error bars) and results shown as mean traces of the $f_{340 \mathrm{~nm}} / f_{380 \mathrm{~nm}}$ ratio \pm SEM (error bars in both directions) with $\mathrm{n}$-values indicating the number of experiments per data point. $\mathrm{Ca}^{2+}$ increases were time delayed because drugs were pipetted into a stationary bath rather than a flow through system. L-carnitine effects were evaluated following a $30 \mathrm{~min}$ preincubation period. Drug stock solutions were prepared with dimethyl sulfoxide (DMSO) and diluted to obtain a nontoxic working concentration wherein DMSO did not exceed $0.1 \%$. Hypertonic stress (i.e., $450 \mathrm{mOsmol} / \mathrm{l}$ ) was imposed by supplementing isotonic Ringer-like solution with $130 \mathrm{mmol} / \mathrm{l}$ D-mannitol to obtain a hypertonic Ringerlike solution.

\section{Scratch wound cell migration assay}

HCKs were incubated in 12-well plates for $48 \mathrm{~h}$ until the cells reached confluence, which was then scratched using a pipette tip. The cell layer was subsequently washed twice with PBS, and then fresh medium was added. The non-treated cells served as controls whereas those treated with $1 \mathrm{mmol} / \mathrm{l}$ L-carnitine were incubated for either another 8 or $24 \mathrm{~h}$. Images were acquired at 0,8 , and $24 \mathrm{~h}$ post treatment using phase-contrast microscopy with a $\times 10$ objective lens. The open wound areas were calculated using Image software (3 replicates).

\section{Immunocytochemistry}

HCK cells were cultured for 3 days in 12-well cell culture plates. Before fixation, HCK cells were stimulated for $24 \mathrm{~h}$ with $5 \mathrm{ng} / \mathrm{ml}$ human recombinant transforming growth factor beta 1 (TGF $\beta 1$, ab50036, Abcam, Cambrigde, United Kingdom), $10 \mu \mathrm{mol} / \mathrm{l}$ capsazepine (CPZ), $1 \mathrm{mmol} / \mathrm{l} \mathrm{L}$-carnitine, $5 \mathrm{ng} / \mathrm{ml}$ TGF $\beta 1$ plus $10 \mu \mathrm{mol} / \mathrm{l} \mathrm{CPZ}$, whereas $5 \mathrm{ng} / \mathrm{ml}$ TGF $\beta 1$ plus $1 \mathrm{mmol} / \mathrm{l}$ L-carnitine with Dulbecco's Modified Eagle Medium (DMEM) served as a control. Vital cells were fixed for $30 \mathrm{~min}$ using $4 \%$ formaldehyde, followed by washing three times with Tris-buffered saline (TBS; pH 7.6, 10 min each). Cells were permeabilized with $0.1 \%$ Triton$\mathrm{X} 100(15 \mathrm{~min})$ and blocked with $5 \% \mathrm{BSA}$ in TBS for $60 \mathrm{~min}$. HCK cells were incubated overnight in a humidified chamber at $4{ }^{\circ} \mathrm{C}$ with primary alpha-smooth muscle actin
( $\alpha$ SMA) antibodies (1:200, 701457, Invitrogen, Carlsbad, California, USA) diluted in $0.8 \%$ BSA in TBS. Fluorescence detection employed $\mathrm{Cy} 3$ conjugated secondary antibodies (1:200, C2306; Sigma-Aldrich, St. Louis, Missouri, USA) and DAPI nuclear counterstaining. Mounted slides were examined using light microscopy (Axio Imager.M2; Zeiss, Jena, Germany).

\section{Planar patch-clamp recordings}

HCK whole cell currents were evaluated as previously described [4]. In brief, a standard intracellular solution containing (mmol/l): $50 \mathrm{CsCl}, 10 \mathrm{NaCl}, 60 \mathrm{CsF}, 20 \mathrm{EGTA}$, and 10 HEPES at $\mathrm{pH} \approx 7.2$ and $\approx 288 \mathrm{mOsmol} / \mathrm{l}$ was applied to the microchip (both provided by Nanion, Munich, Germany). The external solution contained (mmol/l): $140 \mathrm{NaCl}, 4 \mathrm{KCl}, 1$ $\mathrm{MgCl}_{2}, 2 \mathrm{CaCl}_{2}, 5 \mathrm{D}$-glucose monohydrate, and 10 HEPES, $\mathrm{pH} \approx 7.4$ and osmolarity $\approx 298 \mathrm{mOsmol} / \mathrm{l}$. Mean membrane capacitance $(17 \pm 6 \mathrm{pF} ; n=7)$ and mean access resistance $(7$ $\pm 2 \mathrm{M} \Omega ; n=7$ ) were calculated by the software. Series resistances, fast and slow capacitance transients were compensated by the amplifier in conjunction with the PatchMaster software. Current recordings were all leak-subtracted and cells with leak currents above $100 \mathrm{pA}$ were discarded. Cells were depolarized every $5 \mathrm{~s}$ from -60 to $+130 \mathrm{mV}$ in $500 \mathrm{~ms}$ steps (voltage ramp). The holding potential (HP) was set to $0 \mathrm{mV}$ in order to eliminate any possible contribution by voltagedependent $\mathrm{Ca}^{2+}$ channel activity. Experiments were started $\sim 10$ min after breaking into a whole-cell configuration [18]. Resulting currents were normalized using cell membrane capacitance to obtain current density (pA/pF).

\section{Statistical analysis}

Parametric Student's $t$-test for paired and unpaired data was used to determine if the data passed the normality test. Otherwise, the nonparametric Wilcoxon test was used. $P$ values $<0.05$ were considered as significant. All values in the bar charts are shown as means \pm SEM (error bars in both directions). Significance was determined using the GraphPad Prism software (version 5.00 for Windows) (La Jolla, California, USA). The bar charts were generated with the same software. All other plots were generated with the SigmaPlot software version 12.5 for Windows (Systat Software, San Jose, California, USA).

\section{Results}

\section{TRPV1 expression and function in HCK}

Figure 1A provides a result consistent with TRPV1 gene expression based on obtaining the predicted $295 \mathrm{bp}$ 
A
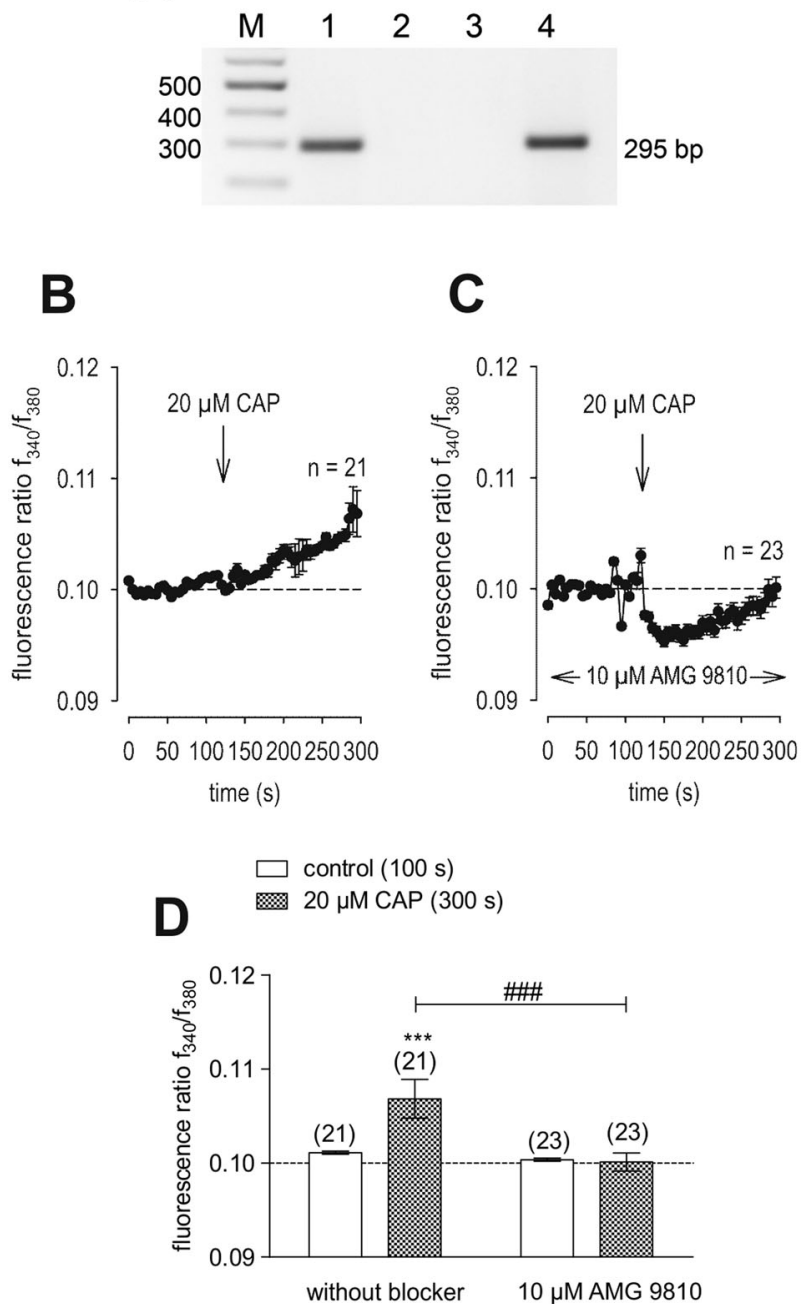

Fig. 1 TRPV1 gene and functional expression in HCK. A RT-PCR analysis of TRPV1 expression using gene specific primers revealed TRPV1 in HCK (lane 1) and HCEC-12 (positive control, lane 4). Template-free negative controls (lane 2: template replaced with $\mathrm{H}_{2} \mathrm{O}$, lane 3: w/o reverse transcriptase in the reverse transcription reaction) gave no bands. $M=100 \mathrm{bp}$ plus DNA ladder. B $20 \mu \mathrm{mol} / \mathrm{l} \mathrm{CAP}$ induced an increase in $\mathrm{Ca}^{2+}$ influx $(n=21)$ in HCK. C Same experiment as shown in $\mathbf{B}$, but in the presence of AMG 9810. AMG $9810(10 \mu \mathrm{mol} / \mathrm{l})$ clearly suppressed the CAP-induced $\mathrm{Ca}^{2+}$ increase even partially below the base line level $(n=23)$. D Summary of the experiments with CAP and AMG 9810 in HCK. The asterisks (*) designate significant increases in $\left[\mathrm{Ca}^{2+}\right]_{\mathrm{i}}$ with $\mathrm{CAP}(t=300 \mathrm{~s} ; n=21$; $\mathrm{p}<0.005$; paired tested) compared to control $(t=100 \mathrm{~s})$. The hashtags (\#) indicate statistically significant differences in fluorescence ratios between CAP with and without AMG $9810(t=300 \mathrm{~s} ; n=21-23 ; p<$ 0.005; nonpaired tested).

RT-PCR product with intron-spanning specific primers. Its identity was confirmed based on the amplicon sequencing result (data not shown). Negative signals in the nontemplate control reactions as well as those obtained with intron-spanning primers confirmed specific amplification of only cDNA and excluded primer binding to genomic DNA. HCEC-12 were used as a positive control since TRPV1 gene expression was documented in earlier studies [16]. In addition, Fig. 1B-D confirm functional TRPV1 expression based on using CAP and the specific TRPV1 blocker AMG 9810 [19]. Specifically, extracellular application of $20 \mu \mathrm{mol} /$ 1 CAP increased the fluorescence ratio $\left(f_{340} / f_{380}\right)$ from 0.1011 $(100 \mathrm{~s}) \pm 0.0002$ to $0.1068 \pm 0.0021$ after $300 \mathrm{~s}(n=21 ; p<$ 0.005 ; Fig. 1B, D). In the presence of $10 \mu \mathrm{mol} / 1 \mathrm{AMG}$ 9810, this CAP-induced $\mathrm{Ca}^{2+}$ increase could be clearly suppressed to $0.1001 \pm 0.0010$ at $300 \mathrm{~s}(n=23 ; p<0.005$; Fig. 1C, D).

Whole cell patch-clamp recordings are also supportive of functional TRPV1 expression in HCK since $10 \mu \mathrm{mol} / 1 \mathrm{CAP}$ induced increases in whole cell currents (Fig. 2). These increases were evaluated based on the plots of the corresponding current voltage relationships at the time points designated as: $\mathrm{A}, \mathrm{B}$ and $\mathrm{C}$ (Fig. 2A, B). At positive potentials, this TRPV1 agonist increased the typical outward TRPV1-like rectifying currents from $172 \pm 71 \mathrm{pA} / \mathrm{pF}$ to $281 \pm 117 \mathrm{pA} / \mathrm{pF}(n=7 ; p<0.05) \quad(n=7 ; p<0.05)$ (Fig. 2B, C). Similarly, maximal inward current amplitudes induced by a voltage step from 0 to $-60 \mathrm{mV}$ increased to $-66 \pm 32 \%$ of control $(n=7 ; p<0.005)$ (Fig. 2D). Maximal outward current amplitudes induced by a voltage step from 0 to $+130 \mathrm{mV}$ increased to $173 \pm 13 \%$ of control (control set to $100 \%)(n=7 ; p<0.01)$ (Fig. 2E).

\section{L-carnitine inhibits TRPV1 activation}

Figure 2 shows that L-carnitine $(1 \mathrm{mmol} / \mathrm{l})$ suppressed CAPinduced increases of whole-cell currents induced by a voltage step from -60 to $+130 \mathrm{mV}$. CAP $(10 \mu \mathrm{mol} / \mathrm{l})$ increased both in- and outward currents, whereas $1 \mathrm{mmol} / \mathrm{l} \mathrm{L}$-carnitine suppressed them from $-32 \pm 13 \mathrm{pA} / \mathrm{pF}$ to $-11 \pm 6 \mathrm{pA} / \mathrm{pF}$ $(n=7 ; p<0.05)$ (Fig. 2A-C) and outward current density was suppressed from $281 \pm 117 \mathrm{pA} / \mathrm{pF}$ to $225 \pm 109 \mathrm{pA} / \mathrm{pF}$ (both $n=7 ; p<0.05$ ) (Fig. 2C). Similarly, maximal inward current amplitudes induced by a voltage step from 0 to $-60 \mathrm{mV}$ decreased them to $112 \pm 16 \%$ of control $(n=7$; $p<0.005$ ) (Fig. 2D) and maximal outward current amplitudes induced by a voltage step from 0 to $+130 \mathrm{mV}$ decreased to $108 \pm 12 \%$ of control $(n=7 ; p<0.01)$ (control set to $100 \%$ ) (Fig. 2E). Similarly, extracellular application of $10 \mu \mathrm{mol} / \mathrm{l}$ CAP increased the fluorescence ratio $\left(f_{340} / f_{380}\right)$ rose from $0.1001(100 \mathrm{~s}) \pm 0.0003$ to $0.1218 \pm 0.0055$ after $300 \mathrm{~s}(n=21 ; p<0.005$; Fig. 3A, C). With HCK cell passage 79 , this increase was suppressed in the presence of $1 \mathrm{mmol} / \mathrm{l} \mathrm{L}$-carnitine $\left(f_{340} / f_{380}=0.1011 \pm 0.0004 ; t=300 \mathrm{~s}\right.$; $n=29 ; p<0.005$ ) (Fig. 3B, C). Similar results were obtained using HCK at earlier cell passages (P69, Fig. 3C). Raising the bath temperature to $>43{ }^{\circ} \mathrm{C}$, which typically activates TRPV1 [20], increased the $\mathrm{f}_{340} / \mathrm{f}_{380}$ ratio from $0.1002 \pm 0.0003(100 \mathrm{~s})$ to $0.1971 \pm 0.0068$ after $300 \mathrm{~s}$ $(n=205 ; p<0.005$; Fig. 4A, C). This increase fell to 

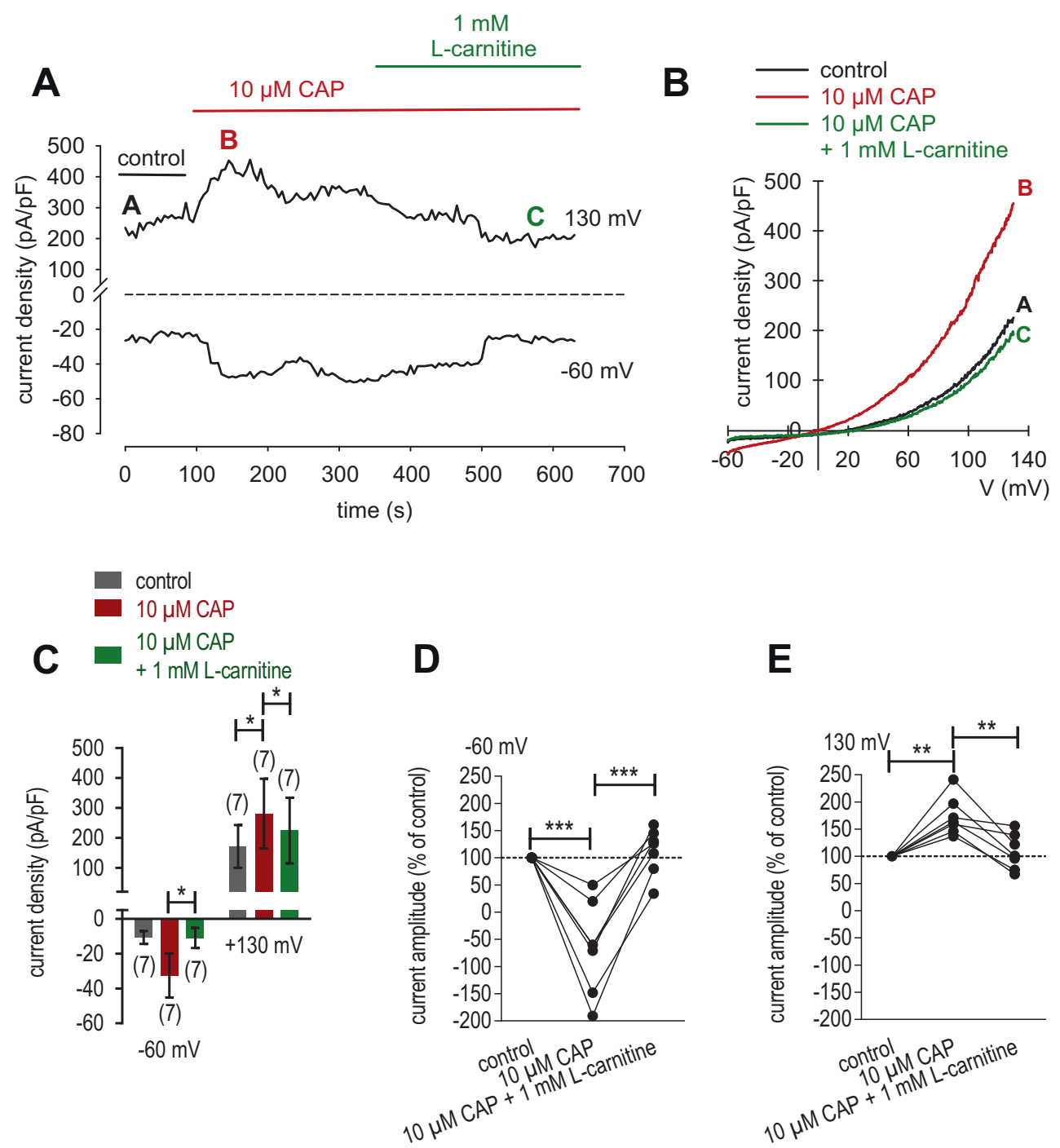

E

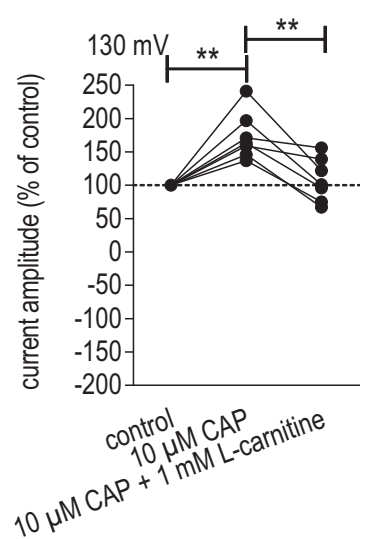

Fig. 2 L-carnitine suppressed CAP-induced increases of whole-cell currents in HCK. A Time course recording of the current increases induced by CAP $(10 \mu \mathrm{mol} / \mathrm{l})$ and declined after application of $1 \mathrm{mmol} / \mathrm{l}$ L-carnitine. B Original traces of CAP-induced current responses to voltage ramps. Current densities are shown before application (labeled as A), during application of $10 \mu \mathrm{mol} / \mathrm{l}$ CAP (labeled as B) and after addition of $1 \mathrm{mmol} / \mathrm{l} \mathrm{L}$-carnitine (labeled as $\mathbf{C}$ ). Calculated current densities obtained by normalizing currents to membrane capacitance as function of imposed voltage were derived from the traces shown in $\mathbf{A}$. C Summary of patch-clamp experiments with CAP and L-carnitine.

$0.1289 \pm 0.0047$ after $300 \mathrm{~s}$ when cells were preincubated with L-carnitine ( $n=33$; $p<0.005)$ (Fig. 4B, C). Hypertonicity irreversibly increased the fluorescence ratio from $0.1002 \pm 0.0001(100 \mathrm{~s})$ to $0.1105 \pm 0.0014$ after $300 \mathrm{~s}$ $(n=55 ; p<0.005$; Fig. 5A, C). Following preexposure to $1 \mathrm{mmol} / \mathrm{l} \mathrm{L}$-carnitine in isotonic medium, the fluorescence ratio remained constant following substitution of $450 \mathrm{mOs}-$ $\mathrm{mol} / \mathrm{l}$ Ringer-like solution containing L-carnitine $(n=73$; $p>0.05$ ) (Fig. 5B, C). In summary, these results confirm that $1 \mathrm{mmol} / \mathrm{l} \mathrm{L}$-carnitine acts as a TRPV1 antagonist in HCK cells.
The asterisks $(*)$ indicate statistically significant differences of wholecell currents with and without CAP $(n=7 ; p<0.05$; paired tested $)$ and significant difference of CAP-induced increased with and without L-carnitine ( $n=7 ; p<0.05$; paired tested). D Maximal negative current amplitudes induced by a voltage step from 0 to $-60 \mathrm{mV}$ are depicted in percent of control values before application of 10 1/l CAP (control set to 100\%). CAP-induced inward currents could be clearly suppressed in the presence of $1 \mathrm{mmol} / \mathrm{l} \mathrm{L}$-carnitine. E Same diagram but related to maximal positive current amplitudes induced by a voltage step from 0 to $+130 \mathrm{mV}$.

\section{L-carnitine suppresses TRPV1-induced HCK migration}

The effect of $1 \mathrm{mmol} / \mathrm{l} \mathrm{L-carnitine} \mathrm{on} \mathrm{HCK} \mathrm{migration} \mathrm{was}$ calculated as a percentage based on the difference between the initial wound area at time point $0 \mathrm{~h}$ and the remaining wound area after $8 \mathrm{~h}$ in the presence and absence of carnitine. Figure $6 \mathrm{~A}-\mathrm{E}$ shows the two wound edges at $0 \mathrm{~h}$ in the control and with $1 \mathrm{mmol} / \mathrm{l} \mathrm{L}$-carnitine after $8 \mathrm{~h}$. The distance separating the wound edges was larger with L-carnitine $(n=30 ; p<0.05)$. After allowing 


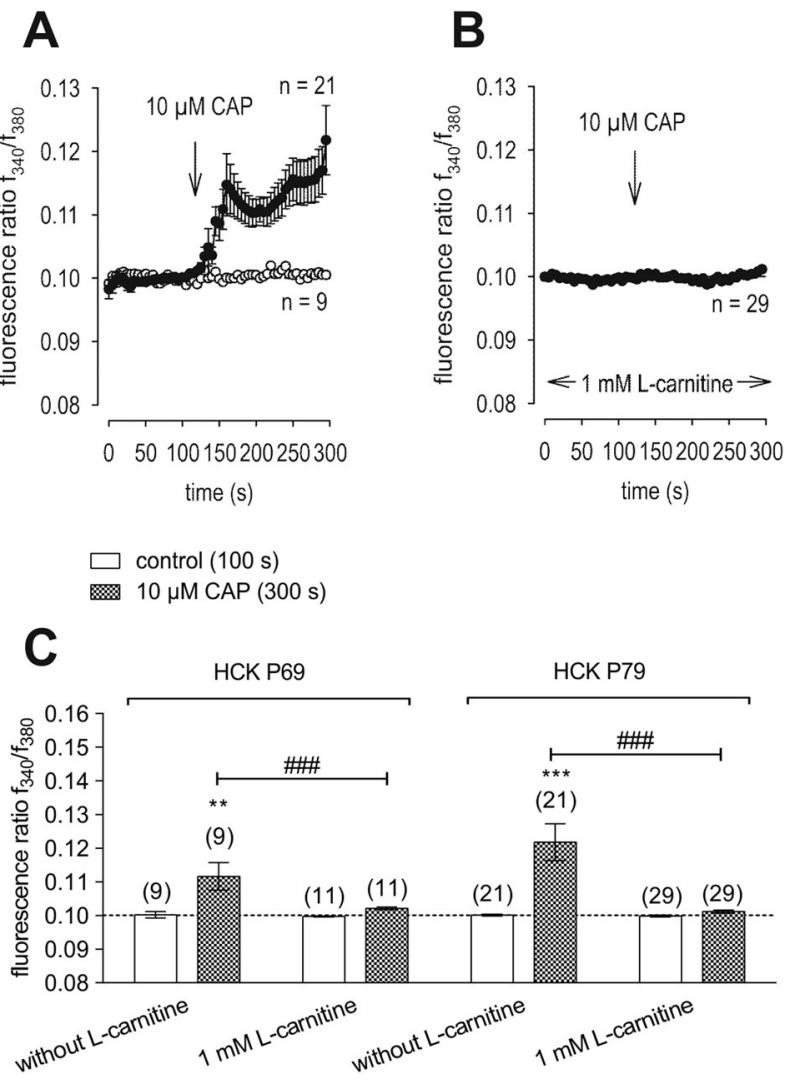

Fig. 3 L-carnitine suppressed CAP-induced increases of intracellular $\mathbf{C a}^{\mathbf{2}+}$ concentration. A $10 \mu \mathrm{mol} / \mathrm{l} \mathrm{CAP}$ induced an increase in $\mathrm{Ca}^{2+}$ influx $(n=21)$ in HCK (P79) whereas non-treated control cells maintained a constant $\mathrm{Ca}^{2+}$ baseline $(n=9)$. B Same experiment as shown in $\mathbf{A}$, but in the presence of L-carnitine (HCK P79). L-carnitine $(1 \mathrm{mmol} / \mathrm{l})$ clearly suppressed the CAP-induced $\mathrm{Ca}^{2+}$ increase $(n=$ 29). C Summary of the experiments with CAP and L-carnitine in HCK from two different cell passages (P69, P79). The asterisks (*) designate significant increases in $\left[\mathrm{Ca}^{2+}\right]_{\mathrm{i}}$ with CAP $(t=300 \mathrm{~s} ; n=9-21 ; p<$ 0.01 at the minimum; paired tested) compared to control $(t=100 \mathrm{~s})$. The hashtags (\#) indicate statistically significant differences in fluorescence ratios between CAP with and without L-carnitine $(t=300 \mathrm{~s}$; $n=9-29 ; p<0.005$; non-paired tested).

HCK migration to proceed for $24 \mathrm{~h}$, the area of the open wound was $30 \%$ larger than in the control (control $=26 \pm$ $7 \% ; 1 \mathrm{mmol} / \mathrm{l} \mathrm{L}$-carnitine $=56 \pm 3 \% ; n=4 ; p<0.05)$, indicating that L-carnitine inhibited wound closure (Fig. 6F-L). Moreover, the TRPV1 channel blocker capsazepine (CPZ) $(10 \mu \mathrm{mol} / \mathrm{l})$ as a positive control almost completely inhibited wound closure since the area of the open wound area was $66 \%$ larger than in the control (control $=26 \pm 7 \% ; 10 \mu \mathrm{mol} / \mathrm{l} \mathrm{CPZ}=92 \pm 4 \% ; n=3-4$; $p<0.005$ ) (Fig. $6 \mathrm{H}, \mathrm{K}, \mathrm{L}$ ). On the other hand, the open wound area in samples with $1 \mathrm{mmol} / \mathrm{l} \mathrm{L}$-carnitine was $15 \%$ smaller than that in samples with $10 \mu \mathrm{mol} / \mathrm{l} \mathrm{CPZ}$ (Fig. 6L). This difference suggests that $\mathrm{CPZ}$ efficacy in inhibiting HCK migration is greater than that of L-carnitine.

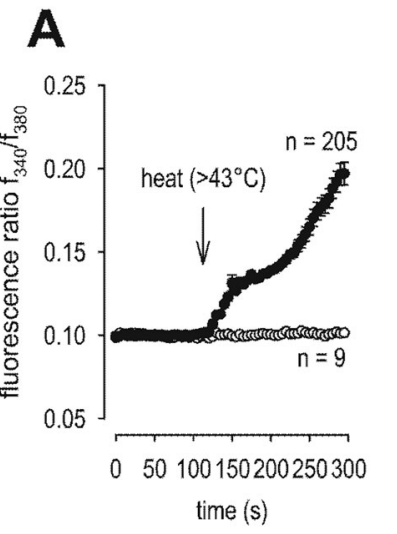

B

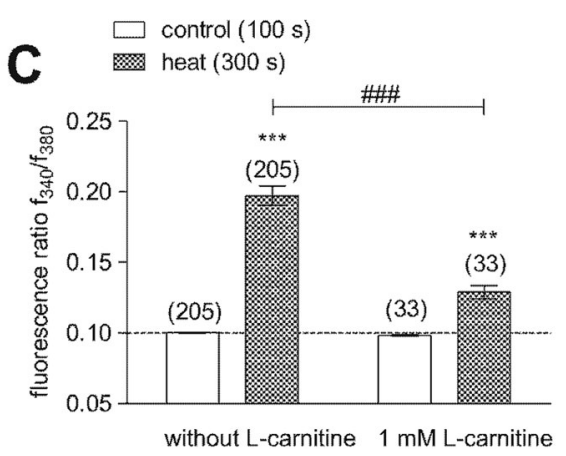

Fig. 4 L-carnitine suppressed heat-induced increases of intracellular $\mathrm{Ca}^{2+}$ concentration. A Heat $\left(>43^{\circ} \mathrm{C}\right)$ induced an increase in $\mathrm{Ca}^{2+}$ influx $(n=205)$ whereas non-treated control cells maintained a constant $\mathrm{Ca}^{2+}$ baseline $(n=9)$. B Same experiment as shown in $\mathbf{A}$, but in the presence of L-carnitine. L-carnitine $(1 \mathrm{mmol} / \mathrm{l})$ partially suppressed the heat-induced $\mathrm{Ca}^{2+}$ increase $(n=33)$. C Summary of the experiments with heat and L-carnitine. The asterisks $(*)$ designate significant increases in $\left[\mathrm{Ca}^{2+}\right]_{\mathrm{i}}$ with heat $(t=300 \mathrm{~s} ; n=205$; $p<0.005$; paired tested) compared to control $(t=100 \mathrm{~s})$. The hashtags (\#) indicate statistically significant differences in fluorescence ratios between heat with and without L-carnitine $(t=300 \mathrm{~s} ; n=33-205$; $p<0.005$; non-paired tested).

\section{L-carnitine suppresses myofibroblast transdifferentiation}

The functional contribution of TRPV1 in controlling the HCK transdifferentiation into myofibroblasts was evaluated by determining if L-carnitine inhibited TGF $\beta$-induced keratocyte transdifferentiation into myofibroblasts [21]. This is a relevant approach since corneal injury leads to opacification as a consequence of TGF $\beta$-induced TRPV1 upregulation followed by increases in keratocyte transdifferentiation into myofibroblasts. Accordingly, the ability of L-carnitine to suppress HCK transdifferentiation was investigated by immunostaining against the myofibroblast biomarker $\alpha$ SMA in the cytoplasm. Preincubation with $5 \mathrm{ng} / \mathrm{ml}$ TGF $\beta$ for $24 \mathrm{~h}$ increased $\alpha$ SMA-positive cytoplasmic staining, which is indicative of myofibroblast transdifferentiation (Fig. 7) [21]. In the untreated control cultures, cytoplasmic $\alpha$ SMA staining was absent. During 


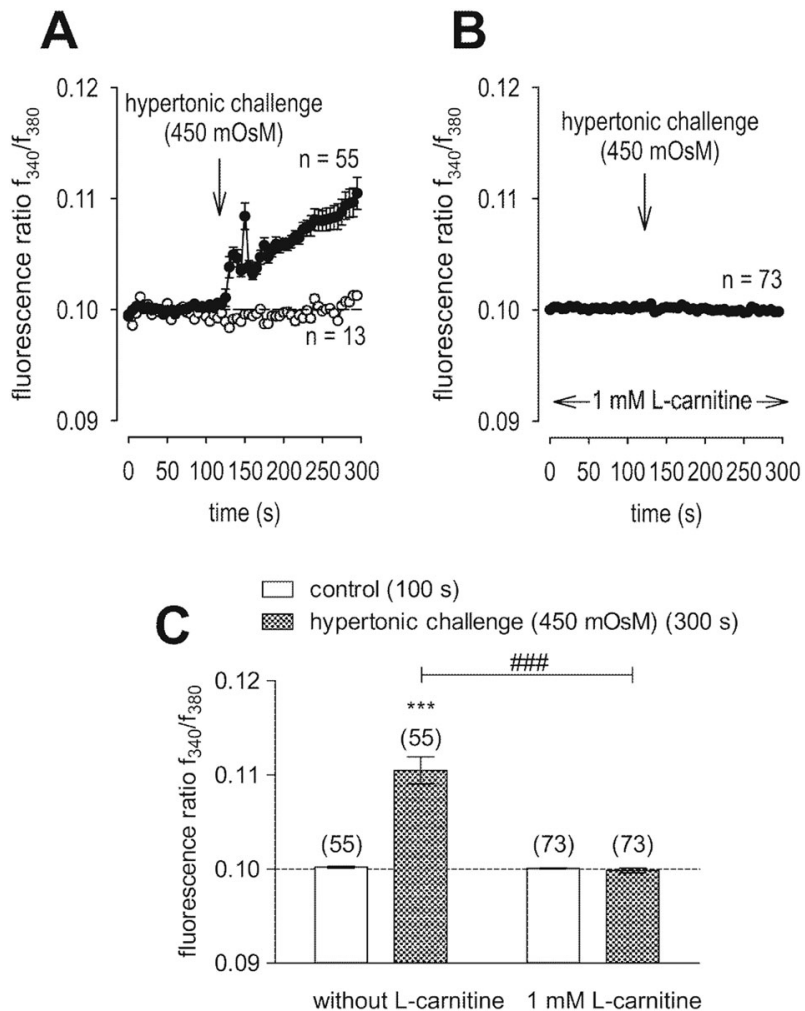

Fig. 5 L-carnitine suppressed hypertonic stress-induced increases of intracellular $\mathbf{C a}^{2+}$ concentration. A Hypertonic challenge (450 $\mathrm{mOsmol} / \mathrm{l})$ induced an increase in $\mathrm{Ca}^{2+}$ influx $(n=55)$ whereas nontreated control cells maintained a constant $\mathrm{Ca}^{2+}$ baseline $(n=13)$. B Same experiment as shown in $\mathbf{A}$, but in the presence of $\mathrm{L}$-carnitine. L-carnitine $(1 \mathrm{mmol} / \mathrm{l})$ clearly suppressed the hypertonic-induced $\mathrm{Ca}^{2+}$ increase $(n=73)$. C Summary of the experiments with hypertonicity and L-carnitine. The asterisks $(*)$ designate significant increases in $\left[\mathrm{Ca}^{2+}\right]_{\mathrm{i}}$ with hypertonicity $(t=300 \mathrm{~s} ; n=55 ; p<0.005$; paired tested) compared to control $(t=100 \mathrm{~s})$. The hashtags (\#) indicate statistically significant differences in fluorescence ratios between hypertonic challenge with and without L-carnitine $(t=300 \mathrm{~s} ; n=55-73$; $p<0.005$; non-paired tested).

exposure to either $10 \mu \mathrm{mol} / \mathrm{l} \mathrm{CPZ}$ or $1 \mathrm{mmol} / \mathrm{l} \mathrm{L}$-carnitine, $\alpha \mathrm{SMA}$ immunostaining was reduced to levels close to those in the untreated cultures. Specifically, in the presence of TGF $\beta 1$ plus L-carnitine, there was a slight reduction in $\alpha$ SMA-positive cytoplasmic staining, whereas TGF $\beta 1$ plus $\mathrm{CPZ}$ resulted in a more prominent reduction in cytoplasmic $\alpha$ SMA immunostaining. Nevertheless, the similarity between these two trends suggests that L-carnitine reduced TRPV1 activation by TGF $\beta$.

\section{Discussion}

\section{Functional TRPV1 expression}

We document here gene and functional TRPV1 expression in an immortalized HCK cell line (Figs. 1, 2A, 3A) based in part on the effects of CAP and AMG 9810, which are validated TRPV1 channel modulators [19, 22]. Its presence agrees with similar previous studies in primary HCK cells and corneal fibroblasts [4, 5]. The electrophysiological responses that are signatures of TRPV1 activity such as outwardly rectifying currents, a reverse potential near $0 \mathrm{mV}$ (Fig. 2B) and CAP-induced current rises as well as increased $\mathrm{Ca}^{2+}$ influxes (Figs. 1-3) are very similar to those described in other corneal cell types [4, 16, 23]. In addition, its invariant expression irrespective of cell passage number also supports the relevance of this cell model. Increased $\mathrm{Ca}^{2+}$ influx upon raising the temperature above $43{ }^{\circ} \mathrm{C}$ (Fig. 4A) or exposure to $450 \mathrm{mOsmol} / 1$ hypertonic stress (Fig. 5A) further indicated functional TRPV1 expression $[24,25]$. These responses are pertinent to the in vivo condition since TRPV1 activation is documented to be induced by such stresses and it is alleged to contribute to dry eye symptomology. Specifically, the imposed hypertonic stress is also relevant because it is an established marker used to diagnose dry eye disease [26-28]. It is likely that this imposed stress is pertinent to dry eye induced ocular pain even though in these patients the hyperosmotic threshold for inducing pain through TRPV1 activation is unclear [29].

\section{L-carnitine suppresses responses linked to TRPV1 activation}

Even though L-carnitine is a TRPV1 antagonist in some other ocular cell types [11], such an effect had not been previously described in immortalized HCK cells. Nevertheless, L-carnitine eye drop supplementation in artificial tears helps relieve some dry eye symptomology [30]. Previous to the current study it was only known that L-carnitine acts as an osmoprotectant and inhibitor of MAPK signaling pathway-induced stimulation of proinflammatory cytokine release $[7,10]$. Here we show that part of therapeutic effect of artificial tears supplemented with L-carnitine likely stems from its inhibition of TRPV1-induced keratocyte transdifferentiation into myofibroblasts. This conclusion is based on showing that L-carnitine suppressed the following TRPV1induced responses: (1) $1 \mathrm{mmol} / \mathrm{l} \mathrm{L-carnitine} \mathrm{reduced} \mathrm{CAP-}$ induced increases of the whole-cell currents (Fig. 2) and corresponding rises in intracellular $\mathrm{Ca}^{2+}$ levels (Fig. 3). (2) L-carnitine reduced both rises in TRPV1 activity induced by hyperosmolarity and a rise in temperature (Figs. 4, 5). Specifically, hyperosmolarity induced by D-mannitol supplementation induced increases in intracellular $\mathrm{Ca}^{2+}$ that could be suppressed by $1 \mathrm{mmol} / \mathrm{l} \mathrm{L}$-carnitine (Fig. 5B, C). This inhibitory effect is similar to the one described in HCjEC [11]. (3) However, L-carnitine is not such an effective antagonist as CPZ since at a concentration 100fold higher than CPZ L-carnitine had inhibitory effects on 

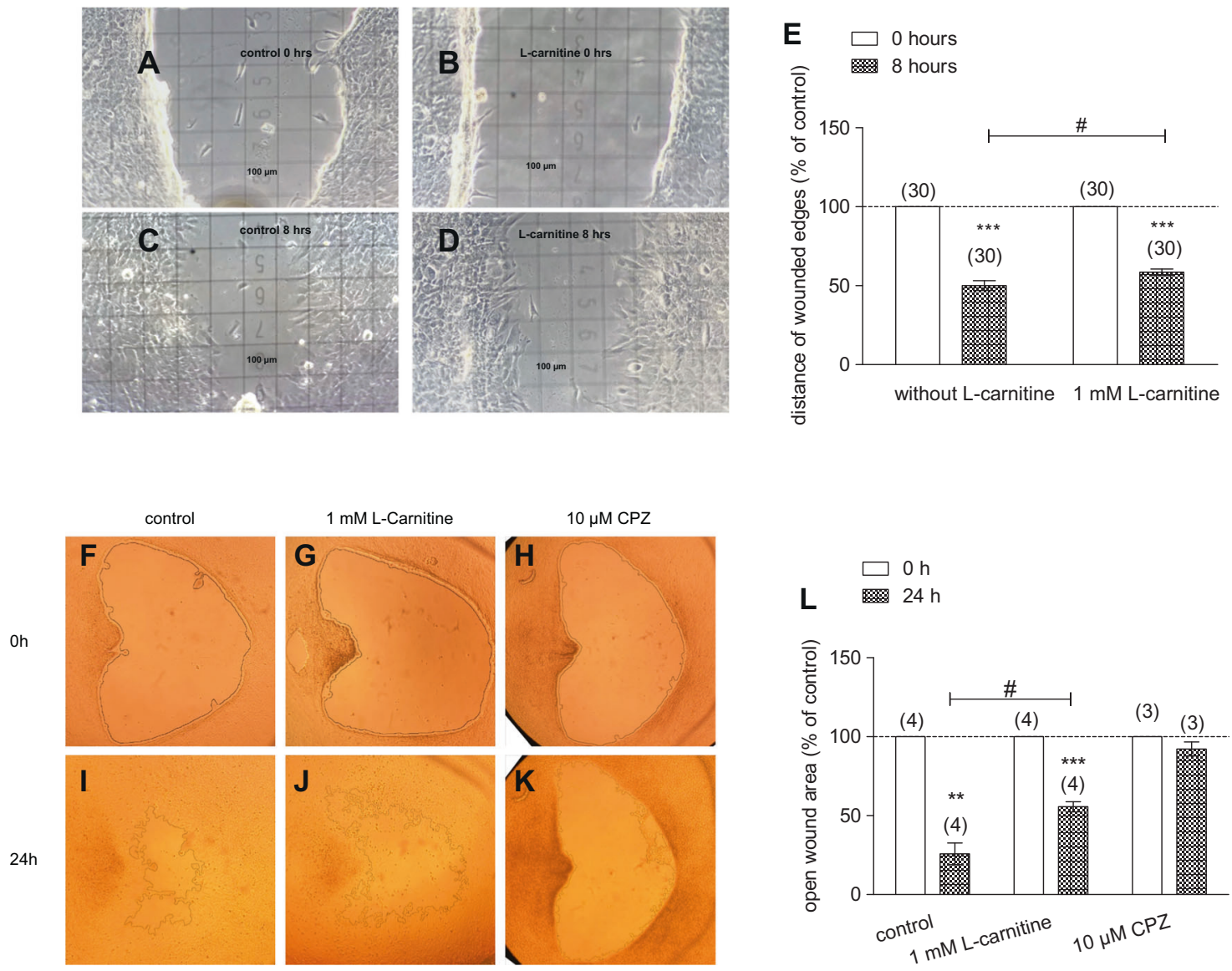

Fig. 6 HCK migration with and without L-carnitine. When HCK reached confluence, a scratch was created with a pipette tip, and floating cells were removed by washing with PBS. The wounded edges and open wound areas were then observed from 0 to 8 and $24 \mathrm{~h}$ of treatment with and without the treatment of $1 \mathrm{mmol} / \mathrm{l} \mathrm{L}$-carnitine. Images of cell migration were acquired and microscopic fields of view of representative experiments are shown. A Light microscopic image of $\mathrm{HCK}$ at $0 \mathrm{~h}$ (control) (square $=100 \mu \mathrm{m}$ ). B HCK in the presence of $1 \mathrm{mmol} / \mathrm{l} \mathrm{L}$-carnitine. C HCK (control) after $8 \mathrm{~h}$. D HCK (L-carnitine) after $8 \mathrm{~h}$. E Summary of the experiment regarding distance of wounded edges (control set to $100 \%$ ). The asterisks $(*)$ designate significant decreases of the distances of the wounded edges (\% of control) $(n=$ $30 ; p<0.005$; paired tested) compared to control. The hashtag (\#)

TRPV1 activation that were smaller than those induced by CPZ.

TRPV1 activation by injury contributes to increases in HCK cell migration and suppression of TRPV1 activity by L-carnitine inhibited HCK migration. Similarly, this response also affects control of the HCK phenotype since L-carnitine also reduced keratocyte transdifferentiation into myofibroblasts (Fig. 7). The role of L-carnitine in modulating cell migration was clarified based on showing that L-carnitine already slightly decelerated HCK cell migration over an $8 \mathrm{~h}$ period (Fig. 6A-D, E). This inhibitory effect became more pronounced after $24 \mathrm{~h}$ (Fig. 6G, J, L). In another study, loss of TRPV1 function impaired healing of an incision stromal wound in mice [3, 31]. This delay was indicates statistically significant difference of the wounded edges with and without the treatment of L-carnitine ( $n=30 ; p<0.05$; non-paired tested). F-K Same experimental design as shown in A-D, but with focus on open wound area between 0 and $24 \mathrm{~h}$. The open wound areas were marked by the software. Furthermore, CPZ was used as a negative control. L Summary of the experiments regarding open wound areas (control set to $100 \%)$. The asterisks $(*)$ designate significant decreases of the open wound areas (\% of control) $(n=3-4$; $p<0.01-0.005$; paired tested) compared to control. In contrast, the open wound areas did not decrease in the presence of CPZ. The hashtag (\#) indicates statistically significant differences in open wound areas (\% of control) between control and L-carnitine $(t=24 \mathrm{~h} ; n=4$; $p<0.05$, unpaired tested).

attributed to a lessening of $\alpha \mathrm{SMA}$ upregulation, fewer terminally differentiated myofibroblasts delimiting the wound edge and less TGF $\beta$ upregulation [3]. These differences may indicate that functional TRPV1 expression contributes to controlling the HCK phenotype since L-carnitine blunted increases in myofibroblast transdifferentiation induced by TGF $\beta$ stimulation of TRPV1, albeit to a lesser extent than CPZ (Fig. 7). Our findings support several preliminary studies showing that blocking TRPV1 suppressed myofibroblast formation and expression of TGF $\beta 1$ in cultured keratocytes or ocular fibroblasts $[31,32]$. The inhibition of TRPV1-driven HCK migration by L-carnitine shown in Fig. 6 is consistent with inhibited wound closure of an incision wound in mice after loss of 
Fig. 7 Myofibroblast activation in HCK after stimulations for $24 \mathrm{~h}$ with $5 \mathrm{ng} / \mathrm{ml}$ human recombinant transforming growth factor beta 1 (TGFß1), $10 \mu \mathrm{mol} / \mathrm{l}$ capsazepine (CPZ), $1 \mathrm{mmol} / \mathrm{l}$ L-carnitine, 5 ng/ml TGFß1 plus $10 \mu \mathrm{mol} / \mathrm{l} \mathrm{CPZ}, 5 \mathrm{ng} / \mathrm{ml}$ TGFß1 plus $1 \mathrm{mmol} / \mathrm{L}$ carnitine and, as a control, with Dulbecco's Modified Eagle Medium (DMEM). Myofibroblasts become apparent as cells that stain positive for $\alpha \mathrm{SMA}$ in the cytoplasm. Nuclear staining of HCK with DAPI (blue) and anti $\alpha$ SMA IF antibody red staining detecting myofibroblasts in HCK. Scale bar $=20 \mu \mathrm{m}$
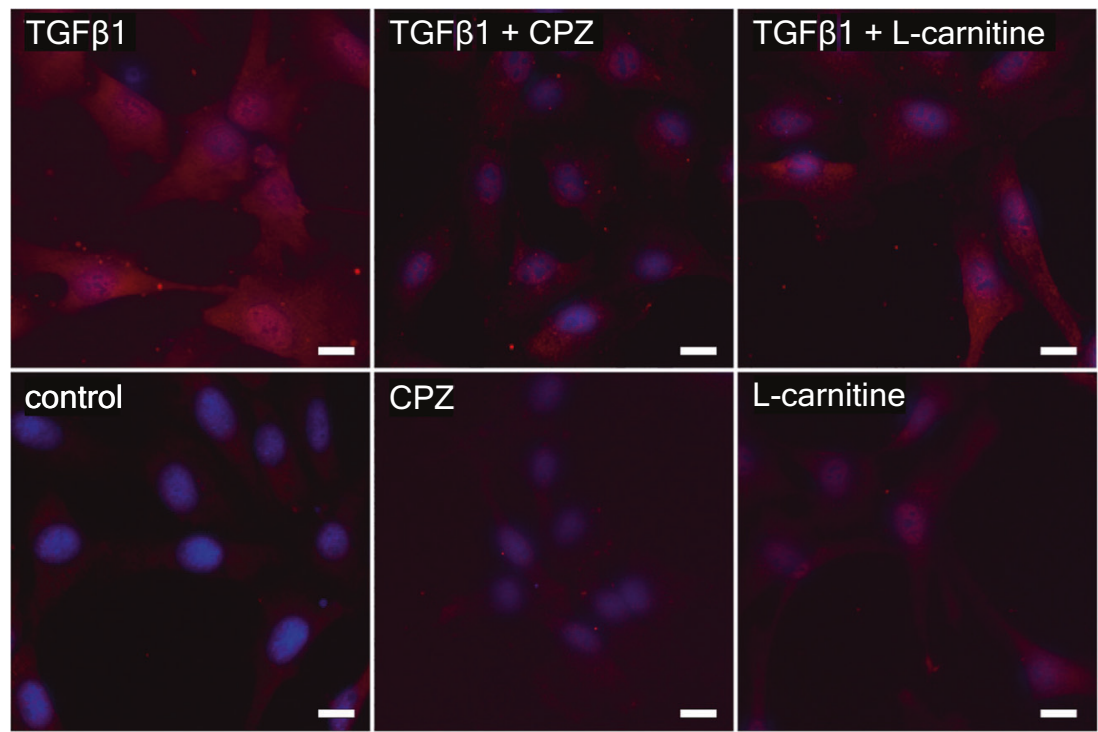

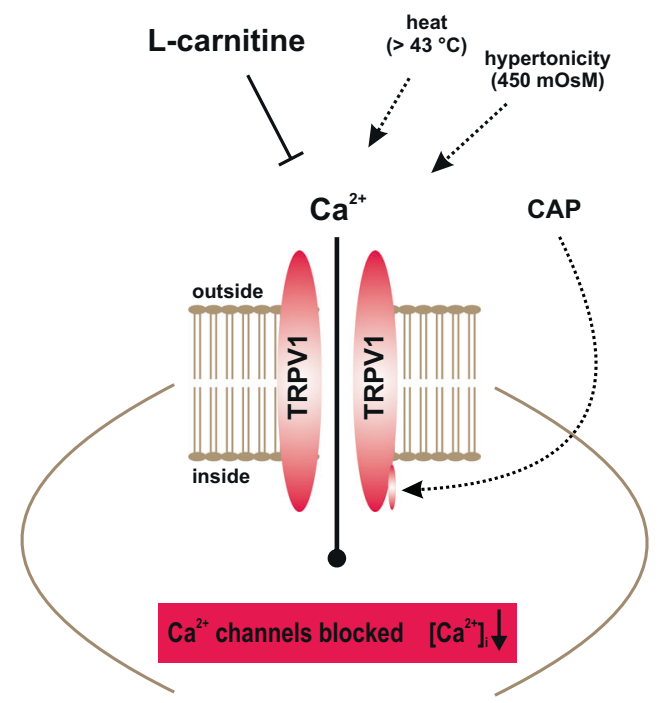

Fig. 8 Simplified representation of the effect of L-carnitine on different TRPV1 channel activation pathways. $\mathrm{Ca}^{2+}$ channels such as TRPs of the TRPV1 subtype (capsaicin receptor) can be selectively activated by CAP (Figs. 2, 3), heat $\left(>43^{\circ} \mathrm{C}\right)$ (Fig. 4) or hypertonic challenge (Fig. 5) (all dotted arrows). L-carnitine was able to suppress TRPV1 activity at all different TRPV1 activation mechanism $(\perp)$ leading overall to a reduced intracellular $\mathrm{Ca}^{2+}$ concentration (Figs. 2-6).

TRPV1 function [3, 31]. Taken together, L-carnitine is a TRPV1 channel antagonist (Fig. 8) that is less efficacious than CPZ in inhibiting HCK migration and transdifferentiation into myofibroblasts.

\section{Possible clinical relevance}

Loss of corneal transparency is a leading cause of blindness worldwide. Such losses can occur subsequent to either penetrating corneal wounds or stromal infections. Such stresses can increase the conversion of keratocytes and fibroblasts into terminally differentiated myofibroblasts, thereby leading to extracellular matrix remodeling, fibrosis, and opacification. Novel strategies are needed to block these TRPV1 mediated responses induced by TRPV1 activation. The results of the current study suggest that blocking TRPV1 activation on keratocytes with antagonists such as carnitine may prove to be a viable approach to suppress corneal opacification in a clinical setting.

\section{Data availability}

The datasets used and/or analyzed during the current study are available from the corresponding author on reasonable request.

Acknowledgements The authors thank Michaela Zorn-Kruppa (University Hospital, Hamburg) for providing the HCK cell line. We also thank for technical assistance provided by the students Iiris Virta, Sirjan Chhatwal, Daria Akbari, Paulina Herzog, Julia Maria Caliman, Julian Francisco Lopez, and Sirjan Chhatwal during their lab rotation and thesis projects, respectively.

Author contributions SM and ET designed the study, analyzed the data, wrote and edited the manuscript. MV and AS performed and evaluated PCR analyses. PSR contributed with his expertise on corneal physiology, discussed data and their interpretation and helped edit the manuscript. UP also contributed with his expertise in medical issues and helped edit the manuscript. ET, HL, SM, MB performed calcium measurements and/or planar patch-clamp recordings as well as plot analyses. TB performed the immunocytochemistry. HL performed scratch assay. ET, MV, HL, MB, and SM created diagrams.

Funding SM and MV were supported by DFG (ME 1706/18-1; VA 179/4-1) for a TRP channel related research project. The planar patchclamp equipment and parts of the photometry setup were partially funded by Sonnenfeld-Stiftung (Berlin, Germany). Open Access funding enabled and organized by Projekt DEAL. 


\section{Compliance with ethical standards}

Conflict of interest The authors declare that the research was conducted in the absence of any commercial or financial relationships that could be construed as a potential conflict of interest.

Publisher's note Springer Nature remains neutral with regard to jurisdictional claims in published maps and institutional affiliations.

Open Access This article is licensed under a Creative Commons Attribution 4.0 International License, which permits use, sharing, adaptation, distribution and reproduction in any medium or format, as long as you give appropriate credit to the original author(s) and the source, provide a link to the Creative Commons license, and indicate if changes were made. The images or other third party material in this article are included in the article's Creative Commons license, unless indicated otherwise in a credit line to the material. If material is not included in the article's Creative Commons license and your intended use is not permitted by statutory regulation or exceeds the permitted use, you will need to obtain permission directly from the copyright holder. To view a copy of this license, visit http://creativecommons. org/licenses/by/4.0/.

\section{References}

1. Jester JV, Moller-Pedersen T, Huang J, Sax CM, Kays WT, Cavangh HD, et al. The cellular basis of corneal transparency: evidence for 'corneal crystallins'. J Cell Sci. 1999;112:613-22.

2. Torricelli AA, Santhanam A, Wu J, Singh V, Wilson SE. The corneal fibrosis response to epithelial-stromal injury. Exp Eye Res. 2016;142:110-8.

3. Nidegawa-Saitoh Y, Sumioka T, Okada Y, Reinach PS, Flanders $\mathrm{KC}$, Liu CY, et al. Impaired healing of cornea incision injury in a TRPV1-deficient mouse. Cell Tissue Res. 2018;374:329-38.

4. Turker E, Garreis F, Khajavi N, Reinach PS, Joshi P, Brockmann $\mathrm{T}$, et al. Vascular endothelial growth factor (VEGF) induced downstream responses to transient receptor potential vanilloid 1 (TRPV1) and 3-Iodothyronamine (3-T1AM) in human corneal keratocytes. Front Endocrinol. 2018;9:670.

5. Yang Y, Yang H, Wang Z, Mergler S, Wolosin JM, Reinach PS. Functional TRPV1 expression in human corneal fibroblasts. Exp Eye Res. 2013;107:121-9.

6. Reinach PS, Pokorny KS. The corneal epithelium: clinical relevance of cytokine-mediated responses to maintenance of corneal health. Arq Bras Oftalmol. 2008;71:80-6.

7. Messmer EM. Osmoprotection as a new therapeutic principle. Ophthalmologe. 2007;104:987-90.

8. Shamsi FA, Chaudhry IA, Boulton ME, Al-Rajhi AA. L-carnitine protects human retinal pigment epithelial cells from oxidative damage. Curr Eye Res. 2007;32:575-84.

9. Corrales RM, Luo L, Chang EY, Pflugfelder SC. Effects of osmoprotectants on hyperosmolar stress in cultured human corneal epithelial cells. Cornea. 2008;27:574-9.

10. Hua X, Su Z, Deng R, Lin J, Li DQ, Pflugfelder SC. Effects of Lcarnitine, erythritol and betaine on pro-inflammatory markers in primary human corneal epithelial cells exposed to hyperosmotic stress. Curr Eye Res. 2015;40:657-67.

11. Khajavi N, Reinach PS, Skrzypski M, Lude A, Mergler S. Lcarnitine reduces in human conjunctival epithelial cells hypertonic-induced shrinkage through interacting with TRPV1 channels. Cell Physiol Biochem. 2014;34:790-803.

12. Hua X, Deng R, Li J, Chi W, Su Z, Lin J, et al. Protective effects of L-carnitine against oxidative injury by hyperosmolarity in human corneal epithelial cells. Investig Ophthalmol Vis Sci. 2015;56: 5503-11.

13. Zorn-Kruppa M, Tykhonova S, Belge G, Diehl HA, Engelke M. Comparison of human corneal cell cultures in cytotoxicity testing. ALTEX. 2004;21:129-34.

14. Zorn-Kruppa M, Tykhonova S, Belge G, Bednarz J, Diehl HA, Engelke M. A human corneal equivalent constructed from SV40immortalised corneal cell lines. Altern Lab Anim. 2005;33:37-45.

15. Engelke M, Zorn-Kruppa M, Gabel D, Reisinger K, Rusche B, Mewes KR. A human hemi-cornea model for eye irritation testing: quality control of production, reliability and predictive capacity. Toxicol In Vitro. 2013;27:458-68.

16. Mergler S, Valtink M, Coulson-Thomas VJ, Lindemann D, Reinach PS, Engelmann K, et al. TRPV channels mediate temperature-sensing in human corneal endothelial cells. Exp Eye Res. 2010;90:758-70.

17. Voets T, Droogmans G, Wissenbach U, Janssens A, Flockerzi V, Nilius B. The principle of temperature-dependent gating in coldand heat-sensitive TRP channels. Nature. 2004;430:748-54.

18. Pusch M, Neher E. Rates of diffusional exchange between small cells and a measuring patch pipette. Pflugers Arch. 1988;411:204-11.

19. Gavva NR, Tamir R, Qu Y, Klionsky L, Zhang TJ, Immke D. et al. AMG 9810 [(E)-3-(4-t-butylphenyl)-N-(2,3-dihydrobenzo[b] [1,4] dioxin-6-yl)acrylamide], a novel vanilloid receptor 1 (TRPV1) antagonist with antihyperalgesic properties.J Pharmacol Exp Ther. 2005;313:474-84.

20. Tominaga M, Caterina MJ. Thermosensation and pain. J Neurobiol. 2004;61:3-12.

21. Yang Y, Wang Z, Yang H, Wang L, Gillespie SR, Wolosin JM, et al. TRPV1 potentiates TGFbeta-induction of corneal myofibroblast development through an oxidative stress-mediated p38SMAD2 signaling loop. PLoS One. 2013;8:e77300.

22. Vriens J, Appendino G, Nilius B. Pharmacology of vanilloid transient receptor potential cation channels. Mol Pharmacol. 2009;75:1262-79.

23. Mergler S, Garreis F, Sahlmuller M, Reinach PS, Paulsen F, Pleyer U. Thermosensitive transient receptor potential channels in human corneal epithelial cells. J Cell Physiol. 2011;226:1828-42.

24. Caterina MJ, Schumacher MA, Tominaga M, Rosen TA, Levine JD, Julius D. The capsaicin receptor: a heat-activated ion channel in the pain pathway. Nature. 1997;389:816-24.

25. Tominaga M, Caterina MJ, Malmberg AB, Rosen TA, Gilbert H, Skinner K, et al. The cloned capsaicin receptor integrates multiple pain-producing stimuli. Neuron. 1998;21:531-43.

26. Jacobi C, Messmer EM. Diagnosis of dry eye disease. Ophthalmologe. 2018;115:433-50.

27. Khanal S, Tomlinson A, McFadyen A, Diaper C, Ramaesh K. Dry eye diagnosis. Investig Ophthalmol Vis Sci. 2008;49:1407-14.

28. Willshire C, Buckley RJ, Bron AJ. Estimating basal tear osmolarity in normal and dry eye subjects. Cont Lens Anterior Eye. 2018;41:34-46.

29. Labetoulle M, Baudouin C, Calonge M, Merayo-Lloves J, Boboridis KG, Akova YA et al. Role of corneal nerves in ocular surface homeostasis and disease. Acta Ophthalmol. 2018. https:// doi.org/10.1111/aos.13844.

30. Baudouin C, Cochener B, Pisella PJ, Girard B, Pouliquen P, Cooper $\mathrm{H}$, et al. Randomized, phase III study comparing osmoprotective carboxymethylcellulose with sodium hyaluronate in dry eye disease. Eur J Ophthalmol. 2012;22:751-61.

31. Okada Y, Reinach PS, Shirai K, Kitano A, Kao WW, Flanders $\mathrm{KC}$, et al. TRPV1 involvement in inflammatory tissue fibrosis in mice. Am J Pathol. 2011;178:2654-64.

32. Saika S, Yamanaka O, Okada Y, Sumioka T. Modulation of Smad signaling by non-TGFbeta components in myofibroblast generation during wound healing in corneal stroma. Exp Eye Res. 2016;142: 40-8. 